\title{
Phosphate structure and lithium environments in lithium phosphorus oxynitride amorphous thin films
}

\author{
M. A. Carrillo Solano ${ }^{1,2} \cdot$ M. Dussauze ${ }^{3} \cdot$ P. Vinatier ${ }^{2} \cdot$ L. Croguennec $^{2} \cdot$ E. I. Kamitsos ${ }^{4}$. \\ R. Hausbrand ${ }^{1}$ • W. Jaegermann ${ }^{1}$
}

\begin{abstract}
Lithium ion-conducting glasses attract wide interest for electrochemical applications like efficient energy storage devices. This work presents a structural study on involved bonding units, based on X-ray photoelectron spectroscopy and infrared spectroscopy, of lithium phosphorus oxide and oxynitride amorphous thin films prepared by RF magnetron sputtering. A thorough consideration of the mid- and farinfrared spectral regions demonstrated structural changes at the phosphate units and the lithium ion environments triggered by nitrogen incorporation and post-deposition thermal treatment. It was found that films prepared by sputtering in pure nitrogen atmosphere have about $75 \%$ of their nitrogen atoms in sites doubly coordinated with phosphorus $(\mathrm{P}-\mathrm{N}=\mathrm{P})$, and the rest in triply coordinated sites. It was shown also that nitrogen incorporation favors the stability of lithium ions, while annealing enhances ionic conductivity of the oxynitride films.
\end{abstract}

Keywords LiPON · IR spectroscopy · Thin film · Lithium phosphorus oxynitride $\cdot$ Glasses

M. A. Carrillo Solano

mcarrillo@surface.tu darmstadt.de

M. Dussauze

marc.dussauze@u bordeaux.fr

1 Technische Universität Darmstadt, Materials Science Department, Surface Science Division, Jovanka Bontschits Str. 2, 64287 Darmstadt, Germany

2 University of Bordeaux, ICMCB, CNRS UPR 9048, F 33600 Pessac, France

3 University of Bordeaux, ISM, CNRS UMR 5255, F 33405 Talence, France

4 Theoretical and Physical Chemistry Institute, National Hellenic Research Foundation, 48 Vassileos Constantinou Avenue, 11635 Athens, Greece

\section{Introduction}

Amorphous ion-conducting films have properties that are appealing for advanced technological applications. The importance of developing these materials as thin films is evident from recent advances in solid-state electrochemical applications. Due to its favorable electrical properties and good electrochemical stability, lithium phosphorus oxynitride (LiPON) glass serves as a good option to be implemented as amorphous electrolyte in all solid-state lithium ion batteries.

The techniques used to produce amorphous thin films include evaporation, pulsed laser deposition (PLD), and sputtering [1-8]. Depending on process conditions and preparation method, thin film materials with different chemical composition, structure, and properties can be made. Several studies comparing the properties of bulk glasses, prepared with traditional melt quenching technique, and thin film amorphous materials, deposited with sputtering, have been made $[9,10]$. Even though both materials had the same nominal composition, differences in the short-range order were reported. In this context, thin film engineering technology has many challenges to overcome in order to fully understand the process by which glassy materials are deposited and thus to correlate composition, structure, and properties with the deposition parameters [11-19].

Most amorphous oxide-based thin films exhibit low ionic conductivity at room temperature. Nitrogen incorporation during the deposition in such oxide-based thin film amorphous materials has been studied thoroughly, since it was found to be a determinant factor for enhancing ionic conductivity [20-23]. Reports on the improvement of ionic conductivity in borates and phosphates by substitution of oxygen for nitrogen have been presented $[9,10,24-26]$. Moreover, studies on postdeposition thermal treatments have also shown improvements on the conductivity properties of glass thin films [22, 27-29]. 
Nevertheless, key concepts are still lacking to progress in understanding the effect of nitrogen incorporation (or annealing) on sputtered LiPON thin film properties and structure.

In this study, lithium phosphorus oxide and oxynitride amorphous thin films were prepared as a function of both gradual nitrogen incorporation and annealing treatments. Structural aspects were examined by X-ray photoelectron spectroscopy (XPS) and infrared spectroscopy (IR). Combining far- and mid-IR spectral region analysis has made evident the effect of nitrogen incorporation on both the phosphate structure and the lithium ion environment. These findings are correlated to the observed chemical stability and ionic conductivity of the studied thin films.

\section{Experimental section}

Lithium phosphates and lithium phosphorus oxynitride thin films were deposited with RF magnetron sputtering, starting from a crystalline 2-in. $\mathrm{Li}_{3} \mathrm{PO}_{4}$ target (Lesker $99.95 \%$ ). Film depositions were done in the DAISY-BAT (Darmstadt Integrated System for Battery Research), a cluster tool based on UHV technology for battery research where deposition chambers are coupled to the XPS analysis chamber [30]. Different nitrogen and argon mixtures, for a total gas flow of $10 \mathrm{sccm}$ with $8 \times 10^{3}$ mbar pressure, were tested. Deposition parameters were employed to obtain film thicknesses of about $1 \mu \mathrm{m}$ (sputtering with power density set to $2.25 \mathrm{~W} / \mathrm{cm}^{2}$ for $4 \mathrm{~h})$ suitable for IR transmittance measurements [9, 10, 24]. Table 1 summarizes the deposition flow rates used for the experiments, from pure argon to pure nitrogen. Samples are named accordingly to the gas flow used $\left(\mathrm{N}_{2}\right.$-Ar flow rate).

Films prepared with the highest nitrogen flow were subsequently annealed at 250,320 , and $380{ }^{\circ} \mathrm{C}$ in vacuum, with a base pressure of $1 \times 10^{7}$ mbar for $1 \mathrm{~h}$. The $\mathrm{Li} / \mathrm{P}$ ratio was determined by inductively coupled plasma atomic emission spectroscopy (ICP-AES) on a Varian 720-ES apparatus. For this purpose, LiPON films were deposited on aluminum foil for $2 \mathrm{~h}$ and then dissolved in acid solution for further analysis. $\mathrm{X}$-ray diffraction patterns were acquired to obtain information about the amorphous nature of the films. The measurements were performed with a Seifert PTS 3003 diffractometer using a $\mathrm{Cu}$ anode operated at $40 \mathrm{~mA}$ and $40 \mathrm{kV}$ and an X-ray mirror on the primary side. On the secondary side, a long Soller slit

Table $1 \quad \mathrm{~N}_{2}$ and Ar flow rates of lithium phosphate and lithium phosphorus oxynitride sputtered films

\begin{tabular}{lll}
\hline Sample $\left(\mathrm{N}_{2}\right.$ Ar flow rate) & $\mathrm{N}_{2}$ flow rate $(\mathrm{sccm})$ & Ar flow rate $(\mathrm{sccm})$ \\
\hline N0 10 & 0 & 10 \\
N5 5 & 5 & 5 \\
N10 0 & 10 & 0 \\
\hline
\end{tabular}

and a graphite monochromator were used to separate the $\mathrm{Cu}$ $\mathrm{K}_{\alpha}$ line.

XPS was used to determine the chemical composition of the surface of the thin films prepared. XPS was performed on each sample directly after every deposition without exposure to ambient air. All core level peaks (Li 1s, P 2p, O 1s, N 1s) and the valence band were recorded using monochromated $\mathrm{Al} \mathrm{K} \mathrm{K}_{\alpha}$ radiation with $\mathrm{hv}=1486.6 \mathrm{eV}$ and a pass energy of $23.50 \mathrm{eV}$.

For the structural analysis of lithium phosphates and lithium phosphorus oxynitride films, IR was used. Thin films were deposited on an undoped silicon wafer. The IR transmission spectra were recorded on a Bruker VERTEX 70v spectrometer, working under vacuum, and equipped with DTGS detectors and two beam splitters (KBr or mylar multilayer). A total of 200 scans were averaged with a resolution of $10 \mathrm{~cm}^{1}$. A glove bag was attached to the IR spectrometer for the handling and exchange of samples under nitrogen atmosphere.

In order to determine the ionic conductivity, electrochemical impedance spectroscopy was performed. For this reason, additional films were prepared on a silicon wafer with a $\mathrm{Si}$ / $\mathrm{SiO}_{2} / \mathrm{TiO}_{2} / \mathrm{Pt}$ layer sequence (GMEK) with a top Au contact. Measurements were carried out in a Zahner IM6 potentiostat, with a frequency range of $1 \mathrm{MHz}-1 \mathrm{~Hz}$.

\section{Results}

\section{Stability of deposited films to air exposure}

The stability of samples prepared in argon and pure nitrogen was studied using infrared measurements in the transmittance mode. The IR spectra of LiPON films, which were either kept under a controlled environment or exposed to air, are shown in Fig. 1.

In all spectra, the sharp peak observed at $610 \mathrm{~cm}^{1}$ corresponds to the strongest lattice mode of the silicon substrate. In the first approach, assignments of the IR bands observed in lithium phosphate thin films can be made by comparison with data reported in the literature for phosphate oxide glasses, as summarized in Table 2.

The IR spectra depicted in Fig. 1 contain all characteristic vibrations of a lithium phosphate network. The shoulder observed between 1200 and $1300 \mathrm{~cm}^{1}$ is assigned to the asymmetric stretching vibrations of $\mathrm{PO}_{2}, v_{\text {as }}\left(\mathrm{PO}_{2}\right)$, of metaphosphate units, while in the range of $900-1100 \mathrm{~cm}{ }^{1}$, asymmetric stretching modes of pyro-, $v_{\text {as }}(\mathrm{P}-\mathrm{O}-\mathrm{P})$ and $v_{\text {as }}\left(\mathrm{PO}_{3}{ }^{2}\right)$, and orthophosphate, $v_{\text {as }}\left(\mathrm{PO}_{4}{ }^{3}\right)$, units can be seen. The infrared bands between 700 and $850 \mathrm{~cm}^{1}$ are associated with symmetric stretching modes of $\mathrm{P}-\mathrm{O}-\mathrm{P}$ linkages, while the broad band observed in the far-IR region, 200-550 $\mathrm{cm}^{1}$, is assigned to vibrations of $\mathrm{Li}$ cations against their sites in the oxide glass matrix $[9,10,35-37]$. 


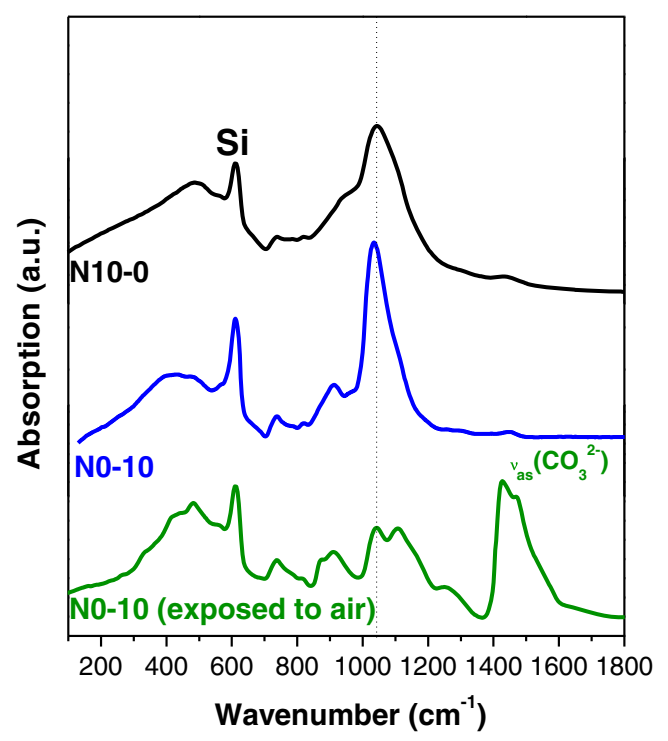

Fig. 1 IR spectra of RF sputtered thin films deposited from a $\mathrm{Li}_{3} \mathrm{PO}_{4}$ target in $\mathrm{Ar}$ or $\mathrm{N}_{2}$ atmosphere (samples named N0 10 and N10 0, respectively). Films kept under $\mathrm{N}_{2}$ and exposed to air are compared. Note that the IR spectrum of the nitrogenated film (N10 0) is not affected by air exposure

On the other hand, the lithium phosphate film (i.e., sample N0-10 deposited under Ar) presents large spectral variations after air exposure (Fig. 1). The most evident difference is observed in the region above $1250 \mathrm{~cm}{ }^{1}$ where two bands appear at 1430 and $1490 \mathrm{~cm}^{1}$. These new IR absorptions can be related to the asymmetric stretching mode of carbonate anions, $v_{\text {as }}\left(\mathrm{CO}_{3}{ }^{2}\right)$, as confirmed also by comparison with attenuated total reflection (ATR) measurements on $\mathrm{Li}_{2} \mathrm{CO}_{3}$ powder (not shown here). Vibrational modes of the phosphate units are also affected when the carbonate species develop: (a) the strongest peak at $1030 \mathrm{~cm}^{1}$, linked to orthophosphate units, decreases in intensity; (b) a shoulder appears at

Table 2 Assignments of the main IR bands expected for amorphous lithium phosphate thin films

\begin{tabular}{|c|c|c|}
\hline Wavenumber $\left(\mathrm{cm}^{1}\right)$ & Assignment & Reference \\
\hline 200550 & $v\left(\mathrm{Li}^{+}\right.$site $)\left(\nu_{\mathrm{L}}, \nu_{\mathrm{H}}\right)$ & {$[31]$} \\
\hline 500600 & $\delta\left(\mathrm{PO}_{2}\right), \delta(\mathrm{O} \mathrm{P} \mathrm{O}), \delta\left(\mathrm{PO}_{3}^{2}\right)$ & {$\left[\begin{array}{ll}32 & 36\end{array}\right]$} \\
\hline 720840 & $v_{\mathrm{s}}(\mathrm{P} \quad \mathrm{O} \quad \mathrm{P})$ & {$\left[\begin{array}{ll}32 & 36\end{array}\right]$} \\
\hline \multicolumn{3}{|l|}{ Orthophosphate } \\
\hline 10301050 & $v_{\mathrm{as}}\left(\mathrm{PO}_{4}{ }^{3}\right)$ & {$\left[\begin{array}{ll}32 & 36\end{array}\right]$} \\
\hline \multicolumn{3}{|l|}{ Pyrophosphate } \\
\hline 900950 & $v_{\mathrm{as}}(\mathrm{P} \quad \mathrm{O} \quad \mathrm{P})$ & {$\left[\begin{array}{ll}32 & 36\end{array}\right]$} \\
\hline$\sim 1110$ & $v_{\mathrm{as}}\left(\mathrm{PO}_{3}^{2}\right)$ & {$\left[\begin{array}{ll}32 & 36\end{array}\right]$} \\
\hline \multicolumn{3}{|l|}{ Metaphosphate } \\
\hline 840980 & $v_{\mathrm{as}}(\mathrm{P} \quad \mathrm{O} \quad \mathrm{P})$ & {$\left[\begin{array}{ll}32 & 36\end{array}\right]$} \\
\hline 12001300 & $v_{\mathrm{as}}\left(\mathrm{PO}_{2}\right)$ & {$\left[\begin{array}{ll}32 & 36\end{array}\right]$} \\
\hline
\end{tabular}

$\nu_{L}$ low frequency components, $\nu_{H}$ high frequency components, $\nu_{s}$ asym metric stretching modes, $\nu_{\text {as }}$ asymmetric stretching modes, $\delta$ bending modes
$1250 \mathrm{~cm}{ }^{1}$ and can be attributed to $v_{\text {as }}\left(\mathrm{PO}_{2}\right)$ of metaphosphate chains; (c) the spectral range $850-950 \mathrm{~cm}^{1}$, attributed to P-O-P vibrations, gains intensity; and (d) the far-IR band gains relative intensity and develops sharper features.

The above spectral variations manifest a higher crosslinked phosphate structure and the growth of phosphate chains. These combined spectroscopic results can be expressed by Eq. 1, which proposes the transformation of orthophosphate units $\left(\mathrm{Li}_{3} \mathrm{PO}_{4}\right)$ to metaphosphate chains $\left(\mathrm{LiPO}_{3}\right)$ and formation of lithium carbonate $\left(\mathrm{Li}_{2} \mathrm{CO}_{3}\right)$.

$$
\mathrm{Li}_{3} \mathrm{PO}_{4}+\mathrm{CO}_{2} \rightarrow \mathrm{LiPO}_{3}+\mathrm{Li}_{2} \mathrm{CO}_{3}
$$

One should notice that the nitrogenated sample suffers no change under air exposure. These results are in accordance with the chemical stabilization of nitrogenated phosphates reported for both lithium and sodium compounds [5, 38, 39].

\section{The structure of lithium phosphate oxynitride thin films and the effect of the nitrogen incorporation}

The ICP-AES results obtained for the $\mathrm{Li} / \mathrm{P}$ ratio of a fully nitrogenated sample (N10-0) was 2.1, with a corresponding experimental uncertainty of $10 \%$. This ratio evidences a lithium loss compared to the composition of the target material $\left(\mathrm{Li}_{3} \mathrm{PO}_{4}\right)$ typically observed for sputtering processes.

The XPS data of O 1s, N 1s, P 2p, and Li 1s core levels from lithium phosphate oxide and oxynitride films are presented in Fig. 2. The $\mathrm{O}$ 1s and $\mathrm{N}$ 1s peaks were decomposed using a Voigt profile for samples N0-10, N5-5, and N10-0. The $\mathrm{N} 1 \mathrm{~s}$ core level peak was fitted with two components. The deconvolution was set to doubly and triply coordinated nitrogen present in the structure, denoted by $\mathrm{Nd}$ and $\mathrm{Nt}$, respectively. The presence of these two types of nitrogen bonding in lithium phosphorus oxynitride films has been proven and studied extensively [40-42]. The studied samples present the main peak contribution arising from nitrogen bonded to two phosphorus atoms, $\mathrm{P}-\mathrm{N}=\mathrm{P}$, which appears at lower binding energy in the spectra. On the other hand, the shoulder observed at higher binding energies corresponds to nitrogen bonded to three phosphorus atoms, $>\mathrm{N}-$. The energy difference between doubly bonded $(\mathrm{Nd})$ and triply bonded $(\mathrm{Nt})$ nitrogen was fitted to be $1.5 \mathrm{eV}$, as reported before [5, 43]. XPS peak position shifts observed in the samples are due to charging effects related to the electronically insulating nature of these oxides [42, 44].

The $\mathrm{O} 1 \mathrm{~s}$ was also decomposed into two components. The main emission observed at low energies corresponds to the non-bridging oxygen (Onb), which can be linked to both bonding environments in $\mathrm{P}-\mathrm{O}-\mathrm{Li}^{+}$and $\mathrm{P}=\mathrm{O}$. However, it is not possible to distinguish these two species due to the resonant bonding in the phosphate tetrahedron $[30,42]$. The shoulder observed at higher binding energies corresponds to 
Fig. 2 XPS profile decomposition of the $\mathrm{O} 1 \mathrm{~s}, \mathrm{~N} 1 \mathrm{~s}$, $\mathrm{P} 2 \mathrm{p}$, and $\mathrm{Li} 1$ s peaks for $\mathrm{N} 10 \mathrm{0}$, N5 5, and N0 10 samples

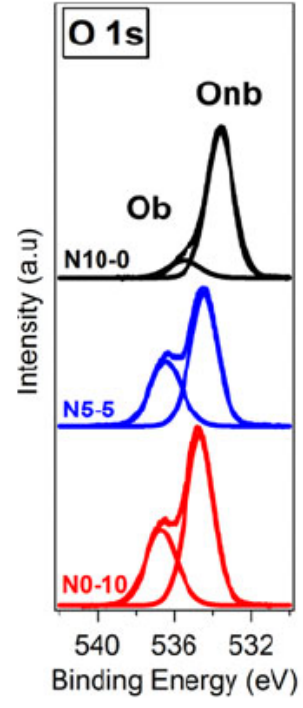

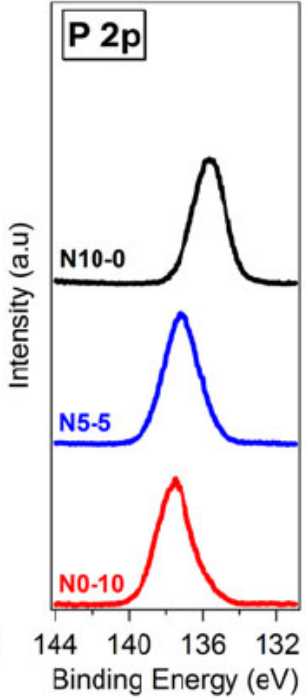

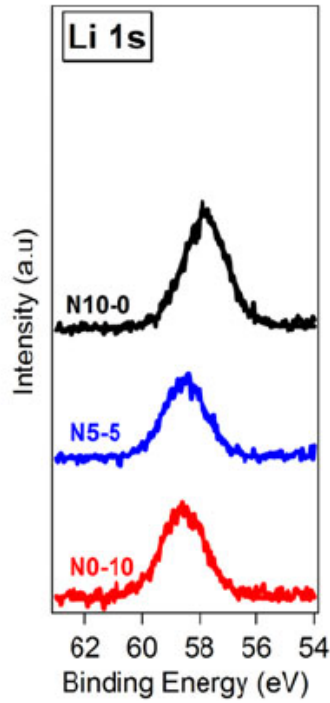

bridging oxygen in $\mathrm{P}-\mathrm{O}-\mathrm{P}$ linkage $(\mathrm{Ob})$. The $\mathrm{Li}$ 1s peak shows a profile with only one lithium component contributing to the emission line. The P $2 p$ was not fitted to identify the spin orbit splitting of the $2 \mathrm{p}$ orbital or to identify the different chemical environments present. Nevertheless, the results of $\mathrm{Li}$ $1 \mathrm{~s}$ and $\mathrm{P} 2 \mathrm{p}$ peaks show symmetric profiles which become sharper with nitrogen incorporation.

Table 3 shows the evolution of the $\mathrm{O} / \mathrm{P}$ and the N/P ratios as well as the $\mathrm{Nt} / \mathrm{Nd}$ ratio compared to $\mathrm{Ob} / \mathrm{Onb}$ ratio as a function of nitrogen incorporation. The oxygen content decreases, while the nitrogen content increases, clearly demonstrating the substitution of oxygen by nitrogen. The relative amount of Onb species tends to increase as the nitrogen content in the gas flow increases.

Figure 3 a presents the infrared absorption spectra of $\mathrm{N} 0-10$, $\mathrm{N} 5-5$, and N10-0 thin films. To better visualize the spectral variations induced by the incorporation of nitrogen, Fig. 3b presents the infrared absorption difference spectra obtained from the normalized IR spectra of the three samples N0-10, N10-0, and N5-5.

All samples have a pronounced peak at $1035 \mathrm{~cm}{ }^{1}$ due to isolated $\mathrm{PO}_{4}{ }^{3}$ orthophosphate units, $\mathrm{v}_{\text {as }}\left(\mathrm{PO}_{4}{ }^{3}\right)$. Increasing the nitrogen flow induces a pronounced decrease in intensity of this peak. On the contrary, a gain in intensity is observed at both lower (peaks at 840 and $960 \mathrm{~cm}^{1}$ ) and higher (peak at

Table 3 Atomic composition and respective $\mathrm{Nt} / \mathrm{Nd}$ and $\mathrm{Ob} / \mathrm{Onb}$ ratios determined by XPS profile decomposition as a function of nitrogen incorporation: N0 10, N5 5, and N10 0

\begin{tabular}{lllll}
\hline Sample $\left(\mathrm{N}_{2}\right.$ Ar flow $)$ & $\mathrm{O} / \mathrm{P}$ & $\mathrm{N} / \mathrm{P}$ & $\mathrm{Ob} / \mathrm{Onb}$ & $\mathrm{Nt} / \mathrm{Nd}$ \\
\hline N0 10 & 3.3 & & 0.5 & \\
N5 5 & 2.5 & 05 & 0.5 & 0.5 \\
N10 0 & 2.2 & 0.9 & 0.1 & 0.3 \\
\hline
\end{tabular}

$1150 \mathrm{~cm}^{1}$ ) wavenumbers. The differences observed in the mid-IR region show how the short-range order is affected with the incorporation of nitrogen. At the first level of interpretation, the infrared spectra suggest that upon nitrogen incorporation, the network becomes more cross-linked, as depicted by the intensity decrease of the peak due to isolated $\mathrm{PO}_{4}{ }^{3}$ units and the intensity increase in the region of asymmetric stretching of phosphate bridges. Comparing the $v_{\text {as }}$ frequency of phosphate bridges, one notices differences between oxide

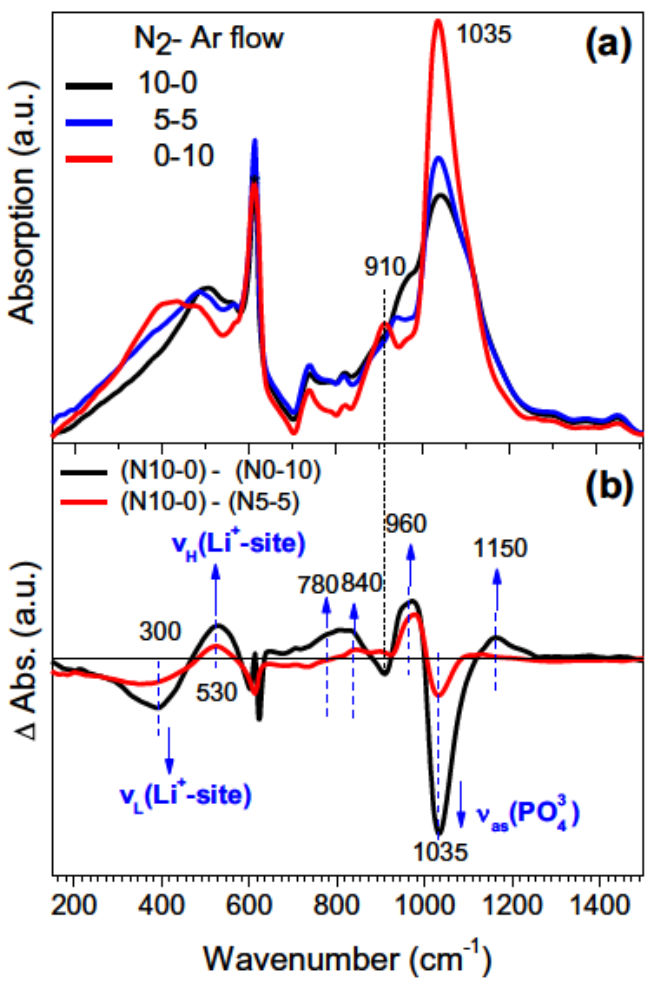

Fig. 3 a IR absorption spectra and $\mathbf{b}$ IR absorption difference spectra of lithium phosphorus oxide and oxynitride thin films: samples N0 10, N5 5 , and N10 0 
and oxynitride networks; in the pure oxide film, $v_{\text {as }}(\mathrm{P}-\mathrm{O}-\mathrm{P})$ appears at $910 \mathrm{~cm}{ }^{1}$ i.e., just in between the two components observed for the oxynitride case at 840 and $960 \mathrm{~cm}^{1}$ (Fig. 3). The assignments of possible $\mathrm{P}-\mathrm{N}$ vibrations will be done in the "Discussion" section.

Focusing on the far-IR region, the broad envelope due to lithium cation vibrations against their sites becomes narrower and the apparent maximum shifts from 400 to $500 \mathrm{~cm}^{1}$ as nitrogen is progressively incorporated in the oxynitride film. This variation evidences a strong influence of nitrogen incorporation on the environments hosting the lithium cations. Kamitsos et al. [31] have observed for alkali oxidecontaining glasses the occurrence of more than one cation motion band in the far-IR originating from the existence of more than one type of cation-hosting anionic sites differing mainly in the coordination of alkali cation. Following this methodology, the far-IR envelope has been analyzed using spectral decomposition based on similar treatments for the far-IR spectra reported for borate, phosphate, and germanate glasses [31, 35, 36, 44, 45]. Figure 4 presents the decomposition of the far-IR region for samples N0-10, N5-5, and N10-0. Peaks corresponding to the Si substrate and to phosphate deformation modes were fixed to 610 and $590 \mathrm{~cm}^{1}$, respectively. The fitting procedure gives satisfactory results with two broad bands peaking at 460 and $330 \mathrm{~cm}^{1}$ for the Li phosphorus oxide film (Fig. 4a) and at 500 and $380 \mathrm{~cm}^{1}$ for the $\mathrm{Li}$ phosphorus oxynitride film (Fig. 4b, c). The narrowing effect

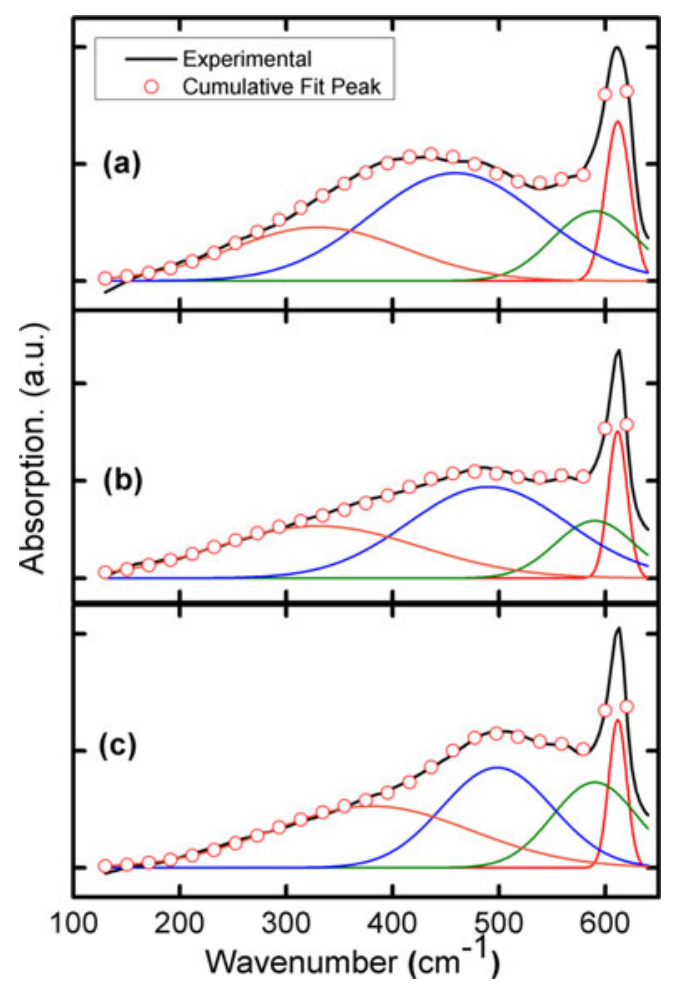

Fig. 4 Spectral decomposition of the far IR region for a non nitrogenated (N0 10), b partially nitrogenated (N5 5), and $\mathbf{c}$ fully nitrogenated (N10 0) lithium phosphorus oxynitride thin films observed on the global far-IR envelope is due to a $65 \%$ decrease of the high-frequency component bandwidth, whereas it remains unchanged for the low-frequency component.

\section{Annealing effect on LiPON thin film structure}

The samples discussed in this section were deposited under nitrogen atmosphere using the same deposition conditions as for sample N10-0 in Table 3. After deposition, thin films were immediately annealed under vacuum (base pressure of $1 \times$ $10^{7} \mathrm{mbar}$ ) for $1 \mathrm{~h}$ at $T_{\mathrm{A}}=250,320$, and $380{ }^{\circ} \mathrm{C}$. Subsequently, IR measurements were performed under controlled atmospheres. However, the spectral features observed for all samples were similar, and we will present in this section only the results for the film annealed at $250{ }^{\circ} \mathrm{C}$.

$\mathrm{XRD}$ measurements were performed on the as-deposited and annealed $\left(250^{\circ} \mathrm{C}\right)$ samples. The diffraction patterns, shown in Fig. 5 and compared to bare silicon substrate, evidence the amorphous structure of the films with a characteristic broad peak around $22^{\circ}$ [11]. The annealed sample additionally showed an increase in intensity reflection, possibly due to a minor gain in ordering of the network, but maintaining the overall peak broadness and thus amorphous nature.

Annealed lithium phosphorus oxynitride thin films were further analyzed with IR spectroscopy. Figure 6a presents the absorption spectra of the as-deposited and annealed oxynitride samples. The spectral variations induced by the post-deposition treatment are presented in Fig. 6b. Similar to nitrogen incorporation, illustrated in the previous section, infrared absorption difference spectra were calculated from the normalized IR spectra of the as-deposited and annealed samples by subtracting the corresponding spectra of films N0-10 (Ar deposition) and N10-0 ( $\mathrm{N}_{2}$ deposition), respectively.

When compared to the as-deposited sample, the annealed layer gives similar IR signature. The minor changes seen at the mid-IR regions with thermal treatment (Fig. 6a) correspond to modifications in the short-range order, evidenced by an increased amount of isolated $\mathrm{PO}_{4}{ }^{3}$ units (peak at $1040 \mathrm{~cm}^{1}$ ). The region

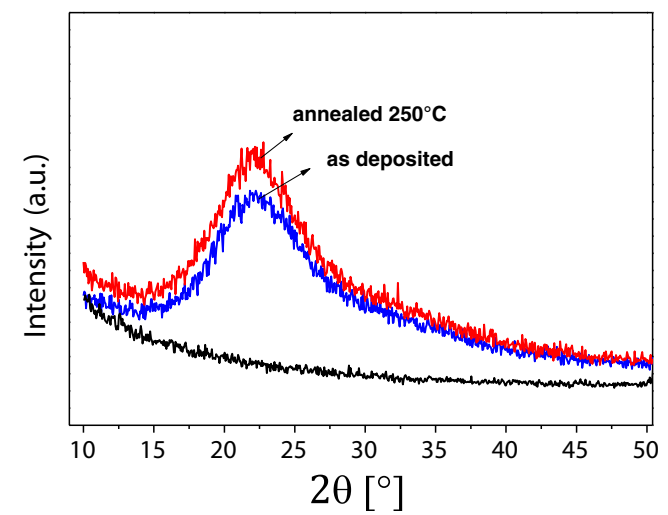

Fig. 5 XRD patterns for as deposited and annealed $\left(250^{\circ} \mathrm{C}\right)$ sputtered LiPON thin film 


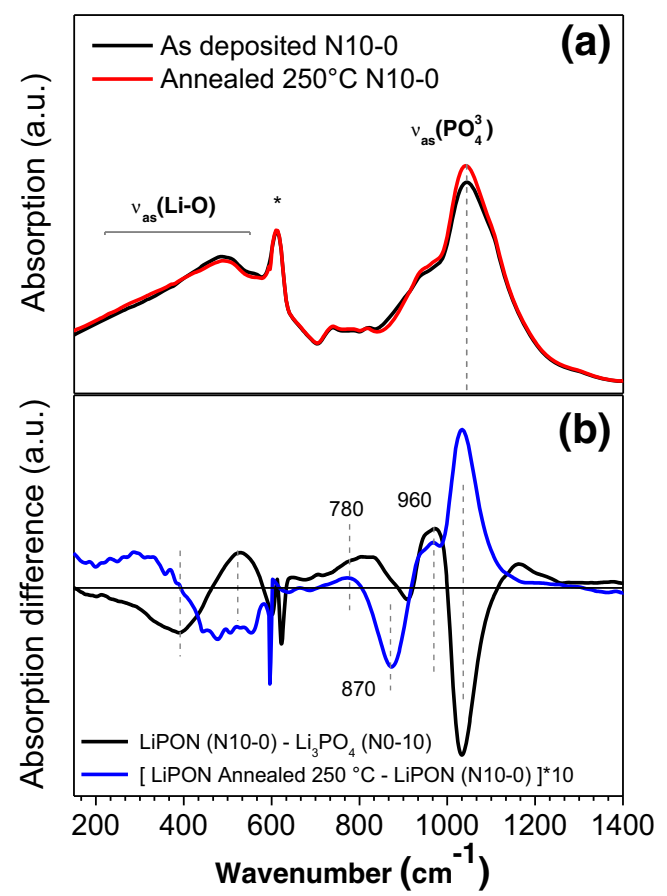

Fig. 6 a IR spectra of lithium phosphorus oxynitride thin film as deposited and annealed at $250{ }^{\circ} \mathrm{C}$ and $\mathbf{b}$ infrared absorption difference spectra of as deposited and annealed samples obtained by subtracting the absorption spectra of thin films deposited under $\mathrm{Ar}$ (N0 10) or $\mathrm{N}_{2}$ flow (N10 0). Note that the absorption difference spectra obtained after anneal ing has been multiplied by 10 to allow relative spectral comparison

linked to the stretching of phosphate bridges is also influenced (Fig. 6b), with an increase observed at high frequency $\left(960 \mathrm{~cm}^{1}\right)$ and a decrease at lower wavenumbers $\left(870 \mathrm{~cm}^{1}\right)$.

In the far-IR, slight changes can be observed related to the two components forming the broad envelope linked to the lithium ion site vibrations. As shown in the difference spectrum (Fig. 6b), the high-frequency component peaking at $500 \mathrm{~cm}^{1}$ has decreased upon annealing, whereas the lowfrequency component has increased.

Comparing the annealing-induced spectral changes to the modifications due to the nitrogen incorporation, we observe an opposite trend concerning both the content of orthophosphate units and the far-IR region. Concerning the asymmetric stretching modes of phosphate bridges $\left(800-1000 \mathrm{~cm}^{1}\right)$, the annealing treatments have modified the relative absorption of the low- and high-frequency components which were both observed upon nitrogen incorporation.

Additional films for the ionic conductivity determination were prepared on a silicon wafer with $\mathrm{Si} / \mathrm{SiO}_{2} / \mathrm{TiO}_{2} / \mathrm{Pt}$ layers, deposited and annealed for the same time as films for IR measurements. An Au contact was sputtered on the resulting films to act as top contact for EIS measurements. Unfortunately, cracking of the oxynitride (LiPON) film was observed for samples annealed at 320 and $380{ }^{\circ} \mathrm{C}$ preventing the determination of the ionic conductivity due to shorts. Table 4 presents the ionic conductivity values of the as-
Table 4 Room temperature ionic conductivities of as deposited and annealed $\left(250^{\circ} \mathrm{C}\right)$ lithium phosphorus oxynitride thin films

\begin{tabular}{ll}
\hline Sample & Ionic conductivity (S/cm) \\
\hline $\mathrm{Li}_{3} \mathrm{PO}_{4}$ & $0.63 .3 \times 10^{7}[7]$ \\
$\mathrm{LiPON}$ & $1.0 \times 10^{6}$ \\
$\mathrm{LiPON}$ (annealed $\left.250{ }^{\circ} \mathrm{C}\right)$ & $2.1 \times 10^{6}$ \\
\hline
\end{tabular}

deposited and annealed $\left(250^{\circ} \mathrm{C}\right) \mathrm{LiPON}$ layers compared to values reported in the literature [7].

The effect of the annealing process resulted in an increase in ionic conductivity, as can be seen in Table 4 . As observed in the IR measurements, for the annealed sample (Fig. 6), thermal-induced formation of isolated units $\left(\mathrm{PO}_{4}{ }^{3}\right)$ and changes in $\mathrm{Li}^{+}$cation vibration trends are opposite to the modifications resulting from nitrogen incorporation, both having a positive effect on the ion mobility [20-23]. Nevertheless, it is important to note that the origin of the changes observed in each case corresponds to different phenomena. On one hand, nitrogen incorporation induces a complete new oxynitride structure, which will be discussed later, while the thermal treatment produces relaxation of constrains present in the "hyperquenched" film and minor structural rearrangements.

\section{Discussion}

To describe the phosphate structure of the oxynitride films studied in this work, the first step is to get knowledge on both lithium and nitrogen content. Chemical composition and structure obtained by ICP and IR spectroscopy, respectively, agree on a loss of lithium compared to the composition of the target. In terms of IR spectroscopy, the oxide phosphate structure can be clearly described as a mixture of orthophosphate and pyrophosphate units.

Upon nitrogen incorporation during sputtering, the chemical bonding of the phosphate matrix should change progressively. For a fixed amount of lithium ions, every two nitrogen ions $\left(\mathrm{N}^{3}\right)$ bonded to the phosphate matrix will remove three oxygen ions $\left(\mathrm{O}^{2}\right)$ from the structure to maintain charge neutrality. Depending on the nature of bonding of the removed oxygen, nitrogen can be incorporated in doubly coordinated $(=\mathrm{N}-)$ and triply coordinated $(-\mathrm{N}<)$ sites with phosphorus atoms. To determine nitrogen content and its coordination, XPS is a very powerful tool. Our data in this work are in good agreement with previous reports from literature. At the maximum of our nitrogen incorporation process, the N/P ratio is close to 1 (sample N10-0, Table 3) and we estimate that about $75 \%$ of the total nitrogen amount is doubly bonded $(=\mathrm{N}-)$. Moreover, for the highest amount of nitrogen incorporated, XPS has evidenced a very low amount of bridging oxygen in the oxynitride phosphate matrix (about $10 \%$ ). In IR 
spectrum, however, the characteristic band of isolated orthophosphate units has decreased in intensity, while an intensity increase in the region of asymmetric stretching of phosphate bridges was observed. In a comparison of XPS and IR data, it must be stated that the relative intensities in XPS are semiquantitative amounts on surface compositions, whereas the changes in IR correspond to qualitative observations of bulk properties. Then, in accordance with literature [5, 13, 41, 43], the data indicate that nitrogen is mainly doubly bonded and related to the formation of bridges between phosphate tetrahedral units.

Figure 7 shows the propositions of oxide and oxynitride structural units in which the nitrogen incorporation simply consists of substitution of bridging oxygen by doubly bonded nitrogen. As noted above, due to the loss of lithium ions during the deposition process, the oxide network is formed as a mixture of orthophosphate and pyrophosphate units, which are depicted in Fig. 7(a, b), respectively.

Then, depending on the value of the $\mathrm{Li} / \mathrm{P}$ ratio, several oxynitride units can be proposed. With a ratio value of $\mathrm{Li}$ / $\mathrm{P}=2$, the oxynitride entity corresponding to pyrophosphate is $\mathrm{Li}_{2} \mathrm{PO}_{2} \mathrm{~N}$ (see Fig. 7(b.1)). For such a lithium concentration, the incorporation of doubly bonded nitrogen forms a chain structure. Interestingly, if one compares oxide and oxynitride chain structures, i.e., the metaphosphate $\mathrm{LiPO}_{3}$ and $\mathrm{Li}_{2} \mathrm{PO}_{2} \mathrm{~N}$, the concentration of lithium is doubled in the oxynitride. Decreasing the size of the chain permits to increase the Li/P ratio. For $\mathrm{Li} / \mathrm{P}=3$, corresponding to the orthophosphate oxide, an oxynitride dimer possessing one non-bridging nitrogen is needed $\left(\mathrm{Li}_{6} \mathrm{P}_{2} \mathrm{O}_{5} \mathrm{~N}_{2}\right.$ in Fig. 7 (a.1)).

Finally, following the experimental evidences showing that nitrogen incorporation is mainly related to the substitution of bridging oxygen by doubly bonded nitrogen, the phosphate network might be described by a mixture of orthophosphate oxide $\mathrm{Li}_{3} \mathrm{PO}_{4}$, with oxynitride dimer, trimer, and chain structures, depending on the $\mathrm{Li} / \mathrm{P}$ ratio.

Nevertheless, one should note that for the orthophosphate oxynitride case (i.e., $\mathrm{Li}_{6} \mathrm{P}_{2} \mathrm{O}_{5} \mathrm{~N}_{2}$ ), there is neither proof in XPS or IR of non-bridging nitrogen in our thin films nor experimental proof of its existence in literature. Thus, we do not expect this particular entity in our oxynitride films, notably because of the lithium deficiency. However, oxynitride dimer
Fig. 7 Proposed clusters for nitrogen incorporation to lithium diphosphate (a.1 and a.2) and triphosphate (a.3) units and to lithium poly phosphate chains (b.1)

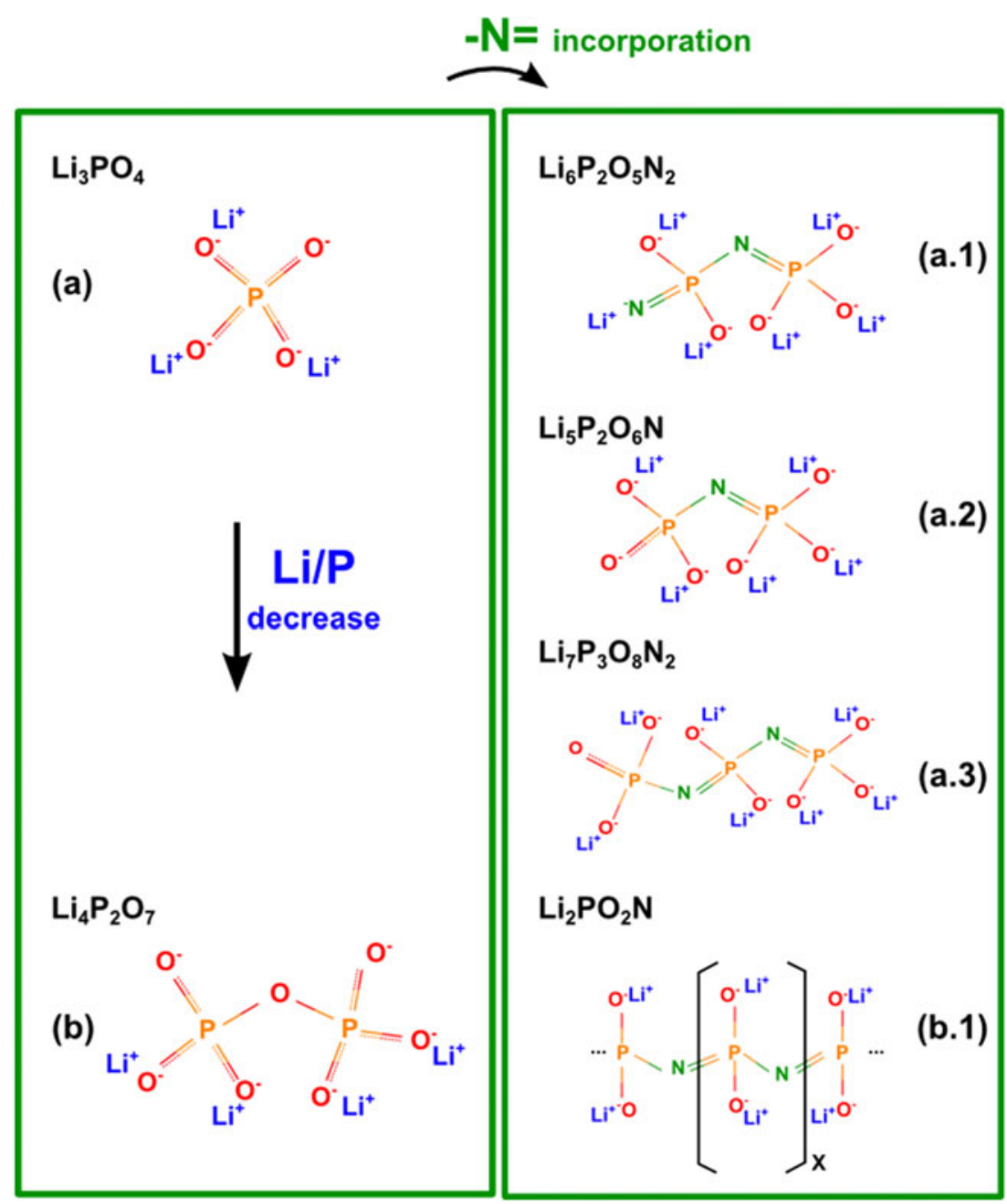


and chain structures were studied by first-principle simulations [47]. Similarly to our propositions, Du and Holzwarth have computed the structure and the related vibrational spectra of a $\mathrm{Li}_{5} \mathrm{P}_{2} \mathrm{O}_{6} \mathrm{~N}$ dimer and $\mathrm{Li}_{2} \mathrm{PO}_{2} \mathrm{~N}$ chains. The vibrational modes with the largest involvement of bridging $\mathrm{N}$ were calculated at 780 and $1130 \mathrm{~cm}{ }^{1}$ in the dimer material $\mathrm{Li}_{5} \mathrm{P}_{2} \mathrm{O}_{6} \mathrm{~N}$ and at 850 and $1120 \mathrm{~cm}^{1}$ in the infinite chain material $\mathrm{Li}_{2} \mathrm{PO}_{2} \mathrm{~N}$.

The agreement with our experimental data is satisfactory, as observed in the difference spectrum (N10-0)-(N0-10) of Fig. 3 showing an increase of absorption upon nitrogen incorporation at $780,840,960$, and $1150 \mathrm{~cm}^{1}$. Similarly to the assignments done for oxide phosphate materials in forms of chains or dimers (see Table 1), it could be possible to assign (i) the low-frequency peaks (i.e., $780,840 \mathrm{~cm}^{1}$ ) to asymmetric stretching of $\mathrm{P}-\mathrm{N}-\mathrm{P}$ bridges in short and long chains, respectively, and (ii) the peak at higher frequency $\left(1150 \mathrm{~cm}^{1}\right)$ to $\mathrm{N}-$ $\mathrm{P}-\mathrm{O}$ stretching vibrations involving a non-bridging oxygen.

The peak observed at $960 \mathrm{~cm}^{1}$ is not predicted by the calculations of Du and Holzwarth of lithium oxynitride chains and dimers [47, 48]. However, as detailed above, the oxynitride structure may tend to form long phosphate chains if the value of the $\mathrm{Li} / \mathrm{P}$ ratio is close to 2 . In such a case, a comparison with oxide metaphosphate glasses suggests the possibility of forming ring structures in the oxynitride network $[35,36]$. Spectral assignments done in the literature for metaphosphate oxide compositions predict the asymmetric stretching of phosphate bridges in ring structures at higher frequency in comparison to chains $[35,36]$. Therefore, the absorption band increasing at $960 \mathrm{~cm}^{1}$ with nitrogen incorporation might be attributed to the presence of rings. In addition, we have observed rearrangements in the spectral domain of phosphate bridges and an increase of the number of $\mathrm{Li}_{3} \mathrm{PO}_{4}$ orthophosphate units after annealing treatments. Following our proposition of assignments, these spectral changes could be linked to the rearrangement of long phosphate chains (decrease at $870 \mathrm{~cm}^{1}$ ) into smaller ones or into rings (increase at $960 \mathrm{~cm}^{1}$ ), which can liberate an isolated orthophosphate unit (increase at $1050 \mathrm{~cm}^{1}$ ). An example of such a structural modification is proposed in Fig. 8.

The effect of nitrogen incorporation on the lithium environment can be evaluated by analyzing far-infrared absorption bands linked to cations motions. As reported for numerous modified glassy systems, we can describe the spectral profile in this region by at least two contributions, at low and high frequency, corresponding to metal cations in at least two distributions of anionic sites. The high-frequency component has been found to be similar to cation vibrations observed in the corresponding crystals $[31,45]$. The low-frequency component was attributed to less favored sites in glass with a higher cation coordination number and a lower negative charge density. It was shown in Fig. 3 that the main effects of nitrogen incorporation on the far-IR absorption are a shift to higher frequency and a narrowing of the high-frequency component. As a first remark, the important narrowing effect (65\% decrease of the high-frequency component bandwidth) observed for the cation motion band denotes a large increase of the metal ion site distribution uniformity and thus a considerable ordering of the local structure around the lithium cations.

Concerning the frequency shift, far-IR spectroscopy is established to be a direct and sensitive tool to study the anionic environment of alkali metal ions [31, 45, 46]. This has been proven by correlating optical basicity and cation motion frequency in several glassy systems [31, 45, 46]. If we consider the interactions between $\mathrm{Li}^{+}$cations and the anionic sites of the oxynitride network as purely ionic (i.e., those interactions should not involve covalency), the cation site vibration can be considered as simple harmonic and the frequency of the mode can be determined using the force constant and the reduced mass of the vibrating cation site system. This force constant can be obtained from the expressions of the electrostatic and repulsive interactions of alkali cations in their site and an analytical form of the frequency of the cation site vibration is obtained, as detailed in [49]:

$v^{2}=\left(\frac{\alpha}{48 \pi^{3} c^{2} \varepsilon_{0}}\right) \frac{q_{C} q_{A}}{\mu r_{0}^{3}}\left(\frac{r_{0}}{\rho}-2\right)$

where $\nu$ is the frequency of the cation site vibration, $q_{\mathrm{C}}$ and $q_{\mathrm{A}}$ are the charges of cation and anionic site, $\mu$ is the reduced mass of vibration, $r_{0}$ is the cation site equilibrium distance, $c$ is the speed of light, $\varepsilon_{0}$ the permittivity of free space, $\alpha$ the pseudo-Madelung constant, and $\rho$ is the repulsion parameter [49]. In a first approximation, one can consider that $q_{\mathrm{C}}, r_{0}$, and $\mu$ do not vary from the oxide to the oxynitride lithium
Fig. 8 Proposed clusters for rearrangements of phosphate chains $(a)$ into ring $(b)$ and orthophosphate $(c)$ units

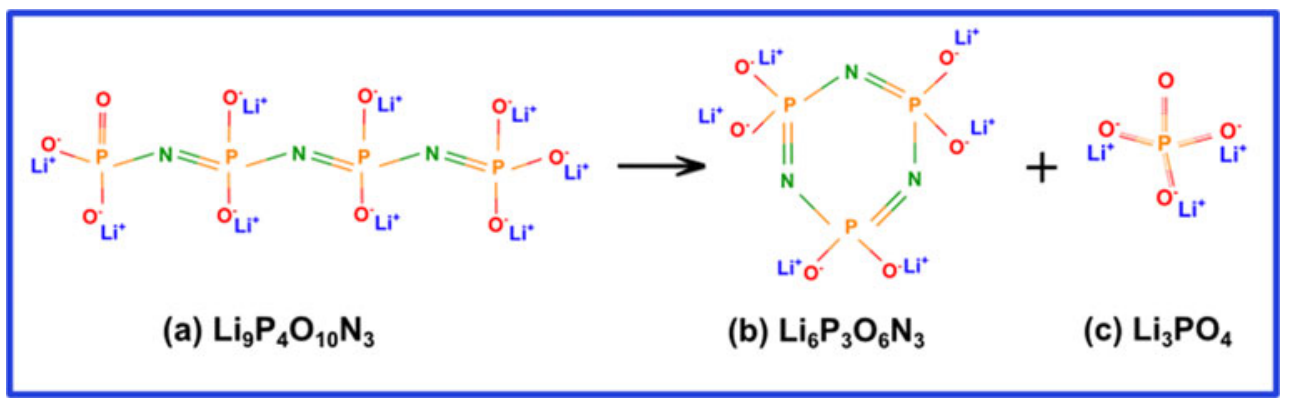


phosphate network. Then, the shift of cation site vibration to higher frequency can be attributed to an increase of the negative charge density $q_{\mathrm{A}}$ at the anionic site. In the present case, the anionic site is dominated by the charge density at the associated non-bridging oxygen, but is also influenced by bridging oxygen or bridging nitrogen atoms in the vicinity. As shown by the oxynitride structure calculated by $\mathrm{Du}$ and Holzwarth, the influence of bridging nitrogen on the lithium environment is much stronger than for bridging oxygen [47, 48]. Their calculations showed that $\mathrm{Li}$ tends to be close to bridging $\mathrm{N}$ in oxynitride as compared to bridging $\mathrm{O}$ in pure phosphorus oxide network. It depicts a non-negligible ionic interaction between $\mathrm{Li}^{+}$cation and bridging nitrogen center. As proposed by Du and Holzwarth, one may consider a more general view concerning the bonding nature of the nitrogen in lithium phosphorus oxynitride network, where a possible scenario would be a nitrogen atom linked with two covalent bonds to phosphorus atoms and a weak ionic bond to lithium. The proposed assignation for the IR bands for oxynitride films are presented in Table 5. These results show how P-N-P bridges appear at similar or lower frequencies compared to the $\mathrm{P}-\mathrm{O}-\mathrm{P}$ bridges in the oxide, evidencing how the force constant observed for the $\mathrm{P}-\mathrm{N}$ bonds is similar or lower than the $\mathrm{P}-\mathrm{O}$ bonds. However, the expected force constant of $\mathrm{N}$ with a double bond should be drastically higher, which is not observed in our IR results. Therefore, this is an indirect confirmation that the bonding nature of $\mathrm{N}$ should not be considered as divalent, but should rather take in account the nonnegligible ionic interaction between $\mathrm{N}_{\text {and }} \mathrm{Li}^{+}$. The ionic interaction, which is much stronger for bridging nitrogen as compared to bridging oxygen, will tend to increase the negative charge density in the $\mathrm{Li}^{+}$site of an oxynitride network and cause the shift to higher frequency observed in the far-IR. This manifests the strong role of doubly covalently bonded bridging nitrogen on the lithium sites, which leads to increase strength of lithium interactions with its anionic site and decrease the related P-N-P force constant.

Finally, one may correlate the information obtained on the nature of the oxynitride phosphate network and the lithium environment with the enhanced properties of the LiPON films, i.e., improved chemical stability and increased ionic conductivity. For the oxide network, we have demonstrated that the chemical instability of the electrolyte is linked to the strong reactivity of lithium cations and oxide anions, which are released from the orthophosphate to pyrophosphate transformation (see Eq. 1). The chemical stability of the oxynitride films can be directly correlated to information obtained from far-IR for (i) stronger interactions between lithium cation and its anionic site (shift to higher frequency) and (ii) increase of the local network ordering around lithium ions (narrowing of the cation motion bandwidth). As for the improved $\mathrm{Li}$ ion transport in the case of phosphorus oxynitride networks, one should consider the redistribution of the negative charge on the phosphate network which determines the energy barriers limiting lithium ion hopping. The stronger involvement of bridging nitrogen atoms in the coordination sphere of lithium ions provides a better distribution of the negative charge density along the phosphate dimer or chain structures as compared to oxide network where the negative charge is mainly located on the non-bridging oxygen sites. In addition, charge delocalization through collective effect along the phosphonitride chains might play a role in improving the lithium ion mobility by inducing a "flexibility" of the negative charge density on the network.

\section{Conclusions}

In this paper, we have investigated the structure of LiPON thin films by XPS and IR spectroscopy, offering complementary information. XPS allows unambiguous distinction of different nitrogen (oxygen) bonding environments and delivers insights regarding composition (determination of $\mathrm{O} / \mathrm{P}$ and N/P ratios). On the other hand, IR spectroscopy is sensitive to the type of structural units present in the film and allows detecting changes in the lithium environment. Combining the results of the two analysis techniques on sputtered films with different nitrogen content, we have proposed specific structural units present in the oxynitride films and discussed the effect of nitrogen incorporation on lithium environment, reactivity, and conductivity.
Table 5 Proposed assignation for IR bands for amorphous sputtered lithium phosphorus oxynitride thin films

\begin{tabular}{|c|c|c|c|c|}
\hline \multicolumn{2}{|l|}{ Oxide } & \multicolumn{3}{|l|}{ Oxynitride } \\
\hline Wavenumber $\left(\mathrm{cm}^{1}\right)$ & Assignment & Wavenumber $\left(\mathrm{cm}^{1}\right)$ & Assignment & Cluster $^{\mathrm{a}}$ \\
\hline 330,460 & $v\left(\mathrm{Li}^{+}\right.$site $)\left(v_{\mathrm{L}}, v_{\mathrm{H}}\right)$ & 380,500 & $v\left(\mathrm{Li}^{+}\right.$site $)\left(v_{\mathrm{L}}, v_{\mathrm{H}}\right)$ & \\
\hline 910 & $v_{\mathrm{as}}(\mathrm{P} \quad \mathrm{O} \quad \mathrm{P})$ pyrophosphate & 780 & $v_{\text {as }}(\mathrm{P} \quad \mathrm{N} \quad \mathrm{P})$ short chains & $7 \mathrm{a} .2$ \\
\hline 1035 & $v_{\mathrm{as}}\left(\mathrm{PO}_{4}^{3}\right)$ & 840 & $v_{\mathrm{as}}(\mathrm{P} \quad \mathrm{N} \quad \mathrm{P})$ long chains & $7 \mathrm{~b} .1$ \\
\hline \multirow[t]{2}{*}{1150} & $v_{\mathrm{as}}\left(\mathrm{PO}_{3}^{2}\right)$ & 960 & $v_{\mathrm{as}}(\mathrm{P} \quad \mathrm{N} \quad \mathrm{P})$ rings & $8 \mathrm{~b}$ \\
\hline & & 1150 & $v_{\mathrm{as}}(\mathrm{N}) \mathrm{P}$ Onb & \\
\hline
\end{tabular}

${ }^{a}$ Clusters from Figs. 7 and 8 


\section{References}

1. Zhao S, Fu Z, Qin Q (2002) A solid state electrolyte lithium phos phorus oxynitride film prepared by pulsed laser deposition. Thin Solid Films 415:108 113. doi:10.1016/S0040 6090(02)00543 6

2. Vereda F, Goldner RB, Haas TE, Zerigian P (2002) Rapidly grown IBAD LiPON films with high Li ion conductivity and electrochem ical stability. Electrochem Solid State Lett 5:A239 A241

3. Stallworth PE, Vereda F, Greenbaum SG et al (2005) Solid state NMR studies of lithium phosphorus oxynitride films prepared by nitrogen ion beam assisted deposition. J Electrochem Soc 152: A516. doi:10.1149/1.1856922

4. Bates JB, Dudney NJ, Gruzalski GR et al (1993) Fabrication and characterization of amorphous lithium electrolyte thin films and rechargeable thin film batteries. J Power Sources 43:103 110 . doi:10.1016/0378 7753(93)80106 Y

5. Wang B (1995) Synthesis, crystal structure, and ionic conductivity of a polycrystalline lithium phosphorus oxynitride with the $\gamma$ $\mathrm{Li}_{3} \mathrm{PO}_{4}$ structure. J Solid State Chem 115:313 323. doi:10.1006/ jssc. 1995.1140

6. Kim B, Cho YS, Lee J G et al (2002) Ion implantation modification of lithium phosphorus oxynitride thin films. J Power Sources 109: 214 219. doi:10.1016/S0378 7753(02)00036 8

7. Kuwata N, Iwagami N, Tanji Y et al (2010) Characterization of thin film lithium batteries with stable thin film $\mathrm{Li}_{3} \mathrm{PO}_{4}$ solid electrolytes fabricated by ArF excimer laser deposition. J Electrochem Soc 157: A521. doi:10.1149/1 3306339

8. Liu W Y, Fu Z W, Li C L, Qin Q Z (2004) Lithium phosphorus oxynitride thin film fabricated by a nitrogen plasma assisted depo sition of E beam reaction evaporation. Electrochem Solid State Lett 7:J36. doi:10.1149/1.1778934

9. Kamitsos EI, Dussauze M, Varsamis C PE et al (2007) Thin film amorphous electrolytes: structure and composition by experimental and simulated infrared spectra. J Phys Chem C 111:8111 8119. doi: $10.1021 / j p 068617 \mathrm{~b}$

10. Kamitsos EI, Dussauze M, Varsamis C PE (2008) Structure of glass thin films by infrared techniques. Phys Chem Glasses Eur J Glass Sci Technol B 49:118 126

11. Hamon Y, Douard A, Sabary F et al (2006) Influence of sputtering conditions on ionic conductivity of LiPON thin films. Solid State Ionics 177:257 261. doi:10.1016/j.ssi.2005.10.021

12. Nimisha CS, Rao KY, Venkatesh G et al (2011) Sputter deposited LiPON thin films from powder target as electrolyte for thin film battery applications. Thin Solid Films 519:3401 3406. doi:10. 1016/j.tsf.2011.01.087

13. Fleutot B, Pecquenard B, Martinez H et al (2011) Investigation of the local structure of LiPON thin films to better understand the role of nitrogen on their performance. Solid State Ionics 186:29 36. doi: 10.1016/j.ssi.2011.01.006

14. Fleutot B, Pecquenard B, Martinez H, Levasseur A (2013) Lithium borophosphate thin film electrolyte as an alternative to LiPON for solder reflow processed lithium ion microbatteries. Solid State Ionics 250:49 55

15. Park HY, Nam SC, Lim YC et al (2006) Effects of sputtering pres sure on the characteristics of lithium ion conductive lithium phos phorous oxynitride thin film. J Electroceram 17:1023 1030. doi:10. 1007/s10832006 89763

16. Roh NS, Lee SD, Kwon HS (1999) Effects of deposition condition on the ionic conductivity and structure of amorphous lithium phos phorus oxynitrate thin film. Scr Mater 42:43 49. doi:10.1016/ S1359 6462(99)00307 3

17. Choi CH, Cho WI, Cho BW et al (2002) Radio frequency magne tron sputtering power effect on the ionic conductivities of LiPON films. Electrochem Solid State Lett 5:A14. doi:10.1149/1.1420926
18. Kim B, Sang Y, Lee J et al (2002) Ion implantation modification of lithium phosphorus oxynitride thin films. J Power Sources 109: 214219

19. Mascaraque N, Fierro JLG, Durán A, Muñoz F (2013) An interpre tation for the increase of ionic conductivity by nitrogen incorpora tion in LiPON oxynitride glasses. Solid State Ionics 233:73 79 . doi:10.1016/j.ssi.2012.12.017

20. Hamon Y, Vinatier P, Kamitsos EI et al (2008) Nitrogen flow rate as a new key parameter for the nitridation of electrolyte thin films. Solid State Ionics 179:1223 1226. doi:10.1016/j.ssi.2008.04.005

21. Kamitsos EI, Dussauze M, Varsamis CP et al (2007) Infrared spec troscopy of Li diborate glassy thin films. J Non Cryst Solids 353: 1818 1823. doi:10.1016/j.jnoncrysol.2007.02.011

22. Fleutot B, Pecquenard B, Martinez H, Levasseur A (2012) Thorough study of the local structure of LiPON thin films to better understand the influence of a solder reflow type thermal treatment on their performances. Solid State Ionics 206:72 77. doi:10.1016/j. ssi.2011.11.009

23. Fleutot B, Pecquenard B, Martinez H, Levasseur A (2013) Lithium borophosphate thin film electrolyte as an alternative to LiPON for solder reflow processed lithium ion microbatteries. Solid State Ionics 249 250:49 55. doi:10.1016/j.ssi.2013.07.009

24. Dussauze M, Kamitsos EI, Johansson P et al (2013) Lithium Ion conducting boron oxynitride amorphous thin films: synthesis and molecular structure by infrared spectroscopy and density functional theory modeling. J Phys Chem C 117:7202 7213. doi:10.1021/ jp401527x

25. Bates J (1992) Electrical properties of amorphous lithium electro lyte thin films. Solid State Ionics 53 56:647 654. doi:10.1016/ $01672738(92) 90442 \mathrm{R}$

26. Wang B, Kwak BS, Sales BC, Bates JB (2008) Ionic conductivities and structure of lithium phosphorus oxynitride glasses. J Non Cryst Solids 183:297 306

27. Chiu K F, Chen C, Lin KM et al (2010) Modification of sputter deposited solid state electrolyte thin films. Vacuum 84:1296 1301. doi:10.1016/j.vacuum.2010.02.006

28. Herbert EG, Tenhaeff WE, Dudney NJ, Pharr GM (2011) Mechanical characterization of LiPON films using nanoindenta tion. Thin Solid Films 520:413 418. doi:10.1016/j.tsf.2011.07.068

29. Neudecker BJ, Zuhr RA, Bates JB (1999) Lithium silicon tin oxynitride $\left(\mathrm{Li}_{\mathrm{y}} \mathrm{SiTON}\right)$ : high performance anode in thin film lithi um ion batteries for microelectronics. J Power Sources 81 82:27 32. doi:10.1016/S0378 7753(98)00202 X

30. Schwöbel A, Hausbrand R, Jaegermann W (2014) Interface reac tions between LiPON and lithium studied by in situ $\mathrm{X}$ ray photo emission. Solid State Ionics 2 5. doi: 10.1016/j.ssi.2014.10.017

31. Kamitsos EI, Chryssikos GD (1998) Alkali sites in glass. Solid State Ionics 105:75 85. doi:10.1016/S0167 2738(97)00451 7

32. Corbridge DEC, Lowe EJ (1954) The infra red spectra of some inorganic phosphorus compounds. J Chem Soc 493 502. doi:10. 1039/JR9540000493

33. Dayanand C, Bhikshamaiah G, Tyagaraju VJ et al (1996) Structural investigations of phosphate glasses: a detailed infrared study of the $\mathrm{x}(\mathrm{PbO})(1 \mathrm{x}) \mathrm{P}_{2} \mathrm{O}_{5}$ vitreous system. J Mater Sci 31:1945 1967. doi: 10.1007/BF00356615

34. Popović L, De Waal D, Boeyens JCA (2005) Correlation between Raman wavenumbers and $\mathrm{P} \mathrm{O}$ bond lengths in crystalline inorganic phosphates. J Raman Spectrosc 36:2 11. doi:10.1002/jrs.1253

35. Velli LL, Varsamis CPE, Kamitsos EI et al (2005) Structural inves tigation of metaphosphate glasses. Phys Chem Glas 46:178 181

36. Varsamis CPE, Kamitsos EI, Minami T, Machida N (2012) Investigation of $\mathrm{CuI}$ containing molybdophosphate glasses by in frared reflectance spectroscopy. J Phys Chem C 116:11671 11681

37. Varsamis C P, Vegiri A, Kamitsos EI (2002) Molecular dynamics investigation of lithium borate glasses: local structure and ion 
dynamics. Phys Rev B 65:104203/1 14. doi:10.1103/PhysRevB. 65.104203

38. Marchand R, Laurent Y, Guyader J et al (1991) Nitrides and oxynitrides: preparation, crystal chemistry and properties. J Eur Ceram Soc 8:197 213. doi:10.1016/0955 2219(91)90096 I

39. Muñoz F, Durán A, Pascual L et al (2008) Increased electrical conductivity of LiPON glasses produced by ammonolysis. Solid State Ionics 179:574 579. doi:10.1016/j.ssi.2008.04.004

40. Bunker BC, Tallant DR, Balfe CA et al (1987) Structure of phos phorus oxynitride glasses. J Am Ceram Soc 70:675 681

41. Marchand R, Agliz D, Boukbir L, Quemerais A (1988) Characterization of nitrogen containing phosphate glasses by $\mathrm{X}$ ray photoelectron spectroscopy. J Non Cryst Solids 103: 3544

42. Brow RK, Reidmeyer MR, Day DE (1988) Oxygen bonding in nitrided sodium and lithium metaphosphate glasses. J Non Cryst Solids 99:178 189. doi:10.1016/0022 3093(88)90470 X

43. Schwöbel A, Precht R, Motzko M et al (2014) Determination of the valence band structure of an alkali phosphorus oxynitride glass: a synchrotron XPS study on LiPON. Appl Surf Sci 321:55 60. doi: 10.1016/j.apsusc.2014.09.174
44. Kim YG, Wadley HNG (2011) The influence of the nitrogen ion flux on structure and ionic conductivity of vapor deposited lithium phosphorus oxynitride films. J Power Sources 196:1371 1377. doi: 10.1016/j.jpowsour.2010.08.115

45. Kamitsos EI, Chryssikos GD, Patsis AP, Duffy JA (1996) Metal ion sites in oxide glasses relation to glass basicity and ion transport. $\mathrm{J}$ Non Cryst Solids 196:249 254. doi:10.1016/0022 3093(95)00595 1

46. Kamitsos EI, Yiannopoulos Y, Jain H, Huang W (1996) Far infrared spectra of alkali germanate glasses and correlation with electrical conductivity. Phys Rev B 54:9775 9783. doi:10.1103/ PhysRevB.54.9775

47. Du YA, Holzwarth NAW (2010) First principles study of LiPON and related solid electrolytes. Phys Rev B 81:184106. doi:10.1103/ PhysRevB.81.184106

48. Du YA, Holzwarth NAW (2008) Effects of O vacancies and $\mathrm{N}$ or $\mathrm{Si}$ substitutions on $\mathrm{Li}^{+}$migration in Li3 PO 4 electrolytes from first principles. Phys Rev B 78:174301. doi:10.1103/PhysRevB.78. 174301

49. Kamitsos EI (1989) Modifying role of alkali metal cations in borate glass networks. J Phys Chem 93:1604 1611. doi:10.1021/ j100341a083 